\title{
Non-Linear Partitioning and Organic Volatility Distributions of Urban Aerosols
}

S. Madronich, ${ }^{a}$ A. Conley, ${ }^{a}$ J. Lee-Taylor, ${ }^{a}$ L. Kleinman, ${ }^{b}$ A. Hodzic ${ }^{a}$ and B. Aumont ${ }^{c}$

(a) National Center for Atmospheric Research, Boulder, Colorado USA

(b) Brookaven National Laboratory, Upton, New York USA

(c) Laboratoire Interuniversitaire des Systèmes Atmospheriques, UMR 7583, CNRS, Université Paris Est Créteil et Université, Paris Diderot, 94010 Créteil, France

\begin{abstract}
Gas-to-particle partitioning of organic aerosols (OA) is represented in most models by Raoult's law, and depends on the existing mass of particles into which organic gases can dissolve. This raises the possibility of non-linear response of particle-phase OA mass to the emissions of precursor volatile organic compounds (VOCs) that contribute to this partitioning mass. Implications for air quality management are evident: A strong non-linear dependence would suggest that reductions in VOC emission would have a more-than-proportionate benefit in lowering ambient OA concentrations. Chamber measurements on simple VOC mixtures generally confirm the non-linear scaling between OA and VOCs, usually stated as a massdependence of the measured OA yields. However, for realistic ambient conditions including urban settings, no single component dominates the composition of the organic particles, and deviations from linearity are presumed to be small. Here we re-examine the linearity question using volatility spectra from several sources: (1) chamber studies of selected aerosols, (2) volatility inferred for aerosols sampled in two megacities, Mexico City and Paris, and (3) an explicit chemistry model (GECKO-A). These few available volatility distributions suggest that urban OA may be only slightly super-linear, with most values of the normalized sensitivity exponent in the range 1.1-1.3, also substantially lower than seen in chambers for some specific
\end{abstract}


aerosols. The rather low exponents suggest that OA concentrations in megacities are not an inevitable convergence of non-linear effects, but can be addressed (much like in smaller urban areas) by proportionate reductions in emissions.

\section{Introduction}

Organic aerosols (OA) are ubiquitous in the atmosphere and especially abundant in urban areas where they are a major part of air pollution. ${ }^{1-4}$ They are associated with volatile organic compounds (VOCs), both those emitted directly and those produced by atmospheric reactions of other VOCs. Great advances have been made over the past decade in understanding OA formation, removal, and properties through synergies of laboratory and chamber measurements, observations from networks, field campaigns, and satellite platforms, and modeling on multiple scales. ${ }^{3-13}$ Still, the relationship between OA and VOCs is not fully understood, particularly for realistic urban mixtures. One of the simplest questions to an air quality model could be: If VOC emissions are changed by one percent, by what percent will OA change? The answer depends of course on so many factors that it is seldom forthcoming.

The possibility of a non-linear dependence of OA on VOCs appears within the absorptive partitioning model formulated by Pankow, ${ }^{14,15}$ in which OA forms a quasi-ideal solution that further enhances gas-to-particle absorption. A corresponding non-linearity is found in smog chamber experiments, under conditions where the yield of OA is seen to increase with OA itself, ${ }^{4,16}$ and often stated as a mass-dependent yield but is in fact a result from the same partitioning considerations. The question arises whether such non-linearities occur also in real urban atmospheres, and if they could be exacerbating already high pollution levels in megacities 
like Mexico City ${ }^{17}$ or Beijing. ${ }^{18}$ Even in less polluted environments, understanding and quantifying this non-linearity would seem a useful step in any regulatory cost-benefit analysis.

There are potentially other sources of non-linearity between OA and VOCs that can be identified and distinguished from those due to absorptive partitioning. For example, variations in VOCs could cause changes in $\mathrm{OH}$ concentrations, with a broad array of consequences for chemical reactions leading to the condensable species that ultimately form OA. These could include changes in ozone $\left(\mathrm{O}_{3}\right)$ and NOx concentrations which in turn could affect both yields and product identities. Although there have been many modeling studies looking at the effect of reducing VOC emissions on OA concentrations [e.g., refs. 19-22] it remains unclear how much of the response arises from non-linear partitioning vs. other chemical changes. Most 3D models ${ }^{11}$ have fairly rudimentary parameterizations for OA formation from VOCs, with largely untested dependencies.

Within the partitioning model framework, the relationship between OA and VOCs is described by the volatility distribution, which is the amount of material (gas + particle) present across a spectrum of saturation concentrations (or vapor pressures, often divided in decadal bins). The volatility distribution is a defining characteristic of an aerosol composed of a mixture of many organic compounds. According to absorptive partitioning theory, mixture components with low volatility will condense nearly completely to the particle phase, while those with intermediate volatility will partition to the particle phase in proportion to the total particle mass, which includes the OA itself. Remarkably, very few volatility distributions for realistic aerosol mixtures have been reported. Here we examine a few available determinations of these volatility spectra, including two urban settings (Mexico City and Paris), several chamber studies, and estimates based on the chemical composition predicted by an explicit chemical box model. We 
use the volatility distributions to estimate the scaling of organic aerosols on VOC loading, OA VOC $^{S}$, where $S$ is a non-linear scaling or sensitivity exponent. The results are shown to be consistent with previously reported field-campaign observations of the rate of growth of OA downwind of intense pollution sources (Mexico City), compared to growth rates in less polluted regions (Eastern U.S.).

\section{Modeling Framework}

Consider a mixture of organic species, indexed $i$, that may be present both in the gas and particle phases with respective amounts $g_{\mathrm{i}}$ and $p_{\mathrm{i}}$ totaling $t_{\mathrm{i}}$,

$$
g_{\mathrm{i}}+p_{\mathrm{i}} \equiv t_{\mathrm{i}}
$$

with all amounts expressed in identical units, e.g., $\mu \mathrm{g} \mathrm{m}^{-3}$. According to quasi-ideal absorptive partitioning theory, ${ }^{4,15}$ the gas to particle ratio is given by Raoult's law,

$$
g_{\mathrm{i}} / p_{\mathrm{i}}=c_{\mathrm{i}} / \Sigma_{\mathrm{i}} p_{\mathrm{i}}
$$

where $c_{\mathrm{i}}$ is the sub-cooled saturation amount of $i$. Combining these equations gives system of non-linear equations,

$$
p_{i}=t_{i} /\left(1+c_{\mathrm{i}} / \Sigma_{\mathrm{i}} p_{\mathrm{i}}\right)
$$

coupled through the total particle phase, $\Sigma_{\mathrm{i}} p_{\mathrm{i}}$. For a single component system, Eq. (3) reduces to

$$
p_{1}=t_{1}-c_{1}
$$

showing that the particle mass increases linearly with the excess above threshold $\left(t_{1}>c_{1}\right)$, rather than being directly proportional to the total, $t_{1}$. For mixtures of multiple components, Eq. (3) must be solved numerically for each $p_{\mathrm{i}}$ as a function of $c_{\mathrm{i}}$ and $t_{\mathrm{i}}$; threshold effects then become 
less pronounced, but may still manifest as a stronger-than-linear increase in particle amount $p_{\mathrm{i}}$ for locally small increases in $t_{\mathrm{i}}$.

A typical urban aerosol mixture may contain thousands of different compounds, and in principle the summations in Eqs. 2 and 3 extend over all species. Following Donahue et al., ${ }^{23}$ and noting that the sub-cooled saturation amount of a species, $c_{\mathrm{i}}$, is a quasi-intensive property, the individual species can be grouped together according to similar $c_{\mathrm{i}}$ values. Here we also use decadal $c_{\mathrm{i}}$ spacing centered on integer values of $\log _{10} c_{\mathrm{i}}$, with the understanding that the subscript $i$ now refers to these decadal volatility bins, rather than to individual molecular species. The volatility distribution, $t_{\mathrm{i}}$, is the total amount of organic material (gas + particle) present in each volatility bin $c_{\mathrm{i}}$, before consideration of partitioning, and is determined by prior processes, e.g. direct emissions, or as a myriad of complex intermediates from the gas-phase oxidation of VOCs. Depending on the functional form $t_{\mathrm{i}}\left(c_{\mathrm{i}}\right)$, gas-particle partitioning may be linear or nonlinear to various extents.

The potential non-linearity is illustrated in Figure 1 by solving Eq. (3) for the simple case of two components, a non-volatile seed $\left(c_{1}=0, p_{1}=t_{1}=1\right)$ and a partly volatile compound with saturation concentration $c_{2}$. The figure shows how the partly volatile compound will partition between the gas and particle phases, as a function of the total available material $\left(t_{2}=\right.$ gas + particle), with each curve representing a possible compound having a different value of $c_{2}$. Two distinct regimes are evident: If seed is abundant (specifically if $c_{2} \lesssim p_{1}=1$ ), the growth will be linear with essentially complete partitioning to the particle phase, over a wide range of $t_{2}$. On the other hand, if $c_{2}$ is significantly larger than the seed, non-linear growth can occur as $t_{2}$ approaches $c_{2}$. In this case, for small burdens $\left(t_{2}<c_{2}\right)$ the particle amount is still sensitive to the amount of seed, but becomes saturated and therefore simply linear when $t_{2}>c_{2}$. 
We define a normalized sensitivity coefficient $S$ as the logarithmic derivative

$$
S=\mathrm{d} \ln P / \mathrm{d} \ln T
$$

where $P=\Sigma_{\mathrm{i}} p_{\mathrm{i}}$ and $T=\Sigma_{\mathrm{i}} t_{\mathrm{i}}$. For simplicity, variations in $T$ were applied uniformly across all species and therefore vapor pressure bins, specifically by multiplying each $t_{\mathrm{i}}$ by the same factor, $X$, so that $S=\mathrm{d} \ln P / \mathrm{d} \ln X$. This is also illustrated in Figure 1 (right axis), where for the case $c_{2}=$ 1000 the sensitivity coefficient reaches a value of 16 (such large near-threshold values are apparently not realized in the atmosphere according to our analyses below).

The Generator of Explicit Chemistry and Kinetics of Organics - Atmosphere (GECKO-A) model was used to simulate the gas-phase chemistry and gas-particle partitioning using a zerodimensional (box) framework. ${ }^{24,25}$ Two cases are considered representing (i) anthropogenic VOCs in Mexico City and its surroundings (MILAGRO field campaign), ${ }^{17}$ and (ii) a terpenedominated forest in Colorado (BEACHON-ROCS field campaign) ${ }^{26}$ both simulations have been described in detail by Lee-Taylor et al. ${ }^{27}$ The Mexico City simulation consisted of two phases, an urban "Eulerian" period lasting 2 days that included emissions, dry deposition, diurnal variation of temperature and PBL height, as well as entrainment (dilution) in both vertical and horizontal dimensions, followed by a 4-day "Lagrangian" outflow that included only horizontal dilution and diurnally invariant temperature. GECKO-A calculates the chemical transformations of gases and particles, tracking a large number $\left(\approx 10^{5}\right)$ of explicit species for which saturation concentrations are known or estimated, allowing their assignment to any volatility binning scheme. For the BEACHON simulations, the biogenic precursor mix was dominated by $\alpha$ - and $\beta$-pinene, limonene, and carene, with trace amounts of isoprene and methyl butenol, based on observations. $^{26}$ 


\section{Results and Discussion}

\subsection{Volatility Distributions}

Volatility distributions have been inferred in controlled chambers using several techniques, including secondary $\mathrm{OA}(\mathrm{SOA})$ growth as a function of reagent consumed, from evaporated fractions remaining through thermal denuders, or from dilution experiments. ${ }^{28}$ All of these methods have complications, e.g., need to estimate enthalpy of vaporization for thermal denuders, changes in chemical composition in all cases, and wall losses. To our knowledge, only two studies reported volatility distributions of OA from ambient urban air: from the Mexico City T0 MILAGRO site, ${ }^{29}$ and from a suburban MEGAPOLI site near Paris. ${ }^{30}$ From models, the only reported urban volatility distributions appear to be those based on our explicit chemical mechanism GECKO-A for MILAGRO and BEACHON. ${ }^{27}$

Reported volatility distributions for various organic aerosols are shown in Table 1, and are essentially the values of $t_{\mathrm{i}}$ in the notation used here. Measurements from different studies are not always comparable directly because they differ in their total amount, $T=\Sigma_{\mathrm{i}} t_{\mathrm{i}}$, as shown in the table under the heading "Sum." Volatility distributions were normalized to $T=1.0 \mu \mathrm{g} \mathrm{m}^{-3}$ by Presto and Donahue, ${ }^{31}$ Grieshop et al. ${ }^{32}$ and Paciga et al. ${ }^{30}$ but to $T=2.5 \mu \mathrm{g} \mathrm{m}{ }^{-3}$ by Robinson et al. ${ }^{8}$ The precise normalization is unimportant, as $T$ can contain large contributions from highly volatile compounds that make only small contributions to the particle amount, $P=\Sigma_{\mathrm{i}} p_{\mathrm{i}}$. What is important, however, is that $T$ be scaled to give (via Eq. 3) particle amounts that are typical of urban atmospheres, e.g. approximately in the typical range 1-10 $\mu \mathrm{g} \mathrm{m}^{-3}$ of OA. Therefore, the $t_{\mathrm{i}}$ values from Table 1 were multiplied by various scale factors, then used in Eq. (3) to calculate the corresponding $p_{i}$ values, which were finally summed to obtain the total particle-phase amount, $P$. The results, shown in Figure 2, are curves describing the growth of particle amount $P$ as a 
function of the total amount $T$. Some curvature is seen even on logarithmic scales, so the slopes were evaluated over the typical range $1-10 \mu \mathrm{g} \mathrm{m}^{-3}$, as also indicated by the placement of the slope values in the figure. These log-log slopes are the sensitivity factors, $S$, giving the (\%) response of particle amount to variations in precursors, and are seen to fall in the range $1.3-1.8$. These are rather high values that could have some regulatory relevance if typical of urban environments.

The volatility distribution for OA collected in Mexico City during MILAGRO was normalized by Cappa and Jimenez ${ }^{29}$ to a particle mass of $17 \mu \mathrm{g} \mathrm{m}^{-3}$, the campaign-average OA value. Values of $t_{\mathrm{i}}$ were obtained directly from their Fig. 5 and used to compute $p_{\mathrm{i}}$ (by solving Eq. 3) and $P$ (which was confirmed as $\approx 17 \mu \mathrm{g} \mathrm{m}^{-3}$ ). Superimposed variations of $t_{\mathrm{i}}$ (10\% increments) were used to evaluate the sensitivity $S=\mathrm{d} \ln P / \mathrm{d} \ln T$, with values shown in Table 1 to range from 1.00 for low-volatility oxygenated SOA, to 1.35 for biomass burning aerosols. On the basis of these sensitivity factors, the non-linearity in Mexico City is judged to be fairly small and decreasingly important (approaching unity) in the order BBOA, HOA, OA, SV-OOA, OOA, LVOOA (respectively biomass burning, hydrocarbon-like, all, semivolatile, oxygenated, and lowvolatility $\mathrm{OA})$.

The volatility distribution in and near Mexico City was also computed with the GECKO-A model. ${ }^{27}$ The saturation vapor pressure for each non-radical molecule was calculated using the method of Nannoolal et al., ${ }^{33}$ followed by grouping of individual molecule concentrations into volatility bins. This procedure was repeated at each time step, allowing us to follow the time evolution of the volatility spectrum. Table 1 shows the volatility distribution at the end of two days of urban processing for Mexico City, and after one day in the terpene-dominated Colorado forest. Both cases show rather low sensitivity exponents, 1.27 for Mexico City and 1.21 for the 
forest, due to the substantial amounts of low volatility organics, c.f. with $c_{\mathrm{i}}$ values of $0.1 \mu \mathrm{g} \mathrm{m}^{-3}$ or lower. Figure 3 shows how the Mexico City volatility evolves over time, for urban air (day 1) and in the outflow after several days of chemical processing. The plume-integrated mass is shown to account for dilution. On the first day, there is relatively little material of very low saturation concentration $c_{\mathrm{i}}$, but this fraction increases progressively during several days due to ongoing oxidation leading to molecules that are generally more functionalized, with higher O/C ratios, ${ }^{9}$ higher oxidation states,${ }^{10}$ higher polarizability, ${ }^{34}$ higher Henry’s law coefficients, ${ }^{35}$ and lower vapor pressures. ${ }^{36}$ Growth in the lower volatility bins is evident and due to photochemical transformations from higher volatility bins, e.g. from $0-2$ on the $\log _{10} c_{\mathrm{i}}$ scale, which are seen to decrease from day 2 to day 5 .

The effect of the aging on the sensitivity coefficient is seen in Figure 4. As might be expected, the increasing fraction of particles with very low volatility acts effectively as a seed for the more volatile compounds, and moves the partitioning further into the seed-dominated nearly linear regime. The highest sensitivities are found in the urban setting (the first day) and may be enhanced by the colder night-time temperatures. On the other hand, the high initial sensitivities may be related to model spin-up with low seed during the first few hours of the simulations.

Organic volatility measurements have also been recently reported for a suburban site $20 \mathrm{~km}$ SW of Paris center. ${ }^{30}$ Values given in Table 1 (estimated from their Fig. 4) are normalized to unity, but were then scaled until the average observed particulate mass concentrations (given in their Table 1) were reached, individually for HOA, OOA (including SV-OOA and LV-OOA), BBOA, OA from cooking (COA), and occasionally of marine origin (MOA). Thus, the sensitivity calculation was carried out for values of $t_{\mathrm{i}}$ scaled to give the observed particle masses, with additionally a $10 \%$ perturbation to obtain $S$. With exception of MOA, all exhibit near-linear 
sensitivities, in the range $1.0-1.2$. Among these, the lowest values are associated with LVOOA, and somewhat higher values for HOA, but also with some unexpected trends e.g., the sensitivity of SV-OOA exceeding that of HOA in summer, that are probably in any case within the range of uncertainties. The case of the marine aerosol is interesting because of its generally more volatile nature, but it should be noted that this represented only a small fraction (a tenth or less) of the total average particulate mass in that study.

\subsection{Other Evidence and Uncertainties}

To summarize Table 1, the few available volatility distributions for Mexico City and Paris imply that OA may be only slightly super-linear, with most values of the sensitivity exponent in the range 1.1-1.3, notably lower than seen in chambers for some specific aerosols. There are a couple of other lines of evidence that are consistent with this result.

Kleinman et al. ${ }^{37}$ used measurements of OA and carbon monoxide (CO) from the DOE G1 aircraft, to compare the rate of production of OA in and near Mexico City to that in the lesspolluted Eastern U.S. With observed OA growth rates normalized by $\Delta \mathrm{CO}$ (plume $\mathrm{CO}-$ background $\mathrm{CO}$ ) concentrations to account for differences in emissions and dilution, the ratio $\mathrm{OA} / \triangle \mathrm{CO}$ is seen to increase over the course of several days downwind from sources, due to ongoing chemistry providing condensable gases. Kleinman et al. ${ }^{37}$ estimated the first-day growth rate in the $\mathrm{OA} / \Delta \mathrm{CO}$ ratio was $62 \mu \mathrm{g} \mathrm{m}^{-3} \mathrm{ppm}^{-1}$ for Mexico City, essentially identical to the values estimated for the NEAQS2002 $\left(66 \mu \mathrm{g} \mathrm{m}^{-3} \mathrm{ppm}^{-1}\right)^{38}$ and NEAQS/ITCT2004 $\left(60 \mu \mathrm{g} \mathrm{m}{ }^{-3}\right.$ $\left.\mathrm{ppm}^{-1}\right)^{39,40}$ field campaigns in the U.S., where CO levels were on average lower by more than a factor of two. Thus, their analysis does not support the notion that OA production is disproportionately strong in a megacity, at least to the extent that $\mathrm{CO}$ may be considered a surrogate for VOCs. Large uncertainties in these estimates were recognized and discussed by 
Kleinman et al. ${ }^{37}$, and include, for example, the need to use the NOx/NOy ratio to estimate when photochemical age reaches one day. Furthermore, emission ratios of many VOCs relative to CO are significantly larger in Mexico City than in the U.S., ${ }^{41}$ complicating direct comparison between the different locations. The apparently good numerical agreement between the three campaigns may thus be fortuitous. Nevertheless, their tentative conclusion, that Mexico City does not display a disproportionate rate of OA production due to non-linear partitioning, is consistent with the conclusions drawn from the volatility distributions, that non-linearity if any is minor.

It might be possible to detect non-linear partitioning using other observations as surrogates, e.g. correlations between particulate organic carbon $(\mathrm{OC}$, the carbon content of $\mathrm{OA})$ and elemental carbon (EC, typically as soot). Because EC is emitted directly, it may bear a simple proportionality to the emitted VOC pool, while OC is subject to non-linear partitioning similarly to OA. A major advantage of considering this ratio is that the $\mathrm{OC}$ and $\mathrm{EC}$ measurements are made rather frequently, and usually as a pair, due to relatively simple instrumentation such as thermo-optical analysis. ${ }^{42,43}$ Thus, OC/EC correlations could provide some indication of OA/VOC scaling. A brief literature review did not show any obvious non-linear relationship, with large variability with OC/EC ratios in the range 1-10. ${ }^{44-46}$ However, many factors are known to affect this ratio and measurements from different locations may not necessarily be comparable. $^{44,47}$

There are several reasons why the above volatility-based sensitivity exponents, small as they are, could be over-estimates. Most notably, variations were made to all $t_{\mathrm{i}}$ simultaneously, as if they were all from the same pool of precursors. In reality, one often regulates only a subset, e.g. aromatics but not biogenics, so the overall sensitivity may be smaller. ${ }^{4}$ But there are also reasons 
why these could be under-estimates. One problem can be seen in Fig. 4, near the beginning of the simulation. Non-linearities are stronger during these first few hours despite the imposition of initial seed $\left(2 \mu \mathrm{g} \mathrm{m}^{-3}\right)$, and may be sensitive to it until enough semi-volatile mass condenses to overwhelm any seed effect. Some caution in this early regime is warranted to ensure that model representations are not overly sensitive to poorly constrained parameters such as initial seed. How this initiation occurs is not completely clear and a number of additional complexities are possible, e.g. from new particle formation processes.

More generally, the sensitivity exponents computed here from volatility distributions are local, in the sense that they predict the response of gas-particle partitioning to small changes in their total amount without regard for the history of the air parcel. A more global sensitivity analysis could consider responses of OA to changes in initial conditions (or emissions), or changes in the nature of the seed. While there may be advantages to each approach, the local sensitivities used here lend themselves to easy interpretation in terms of local partitioning.

\section{Conclusions}

The urban volatility distributions derived from measurements in Mexico City and Paris, and from simulations with the GECKO-A explicit chemical model, all indicate that in complex urban mixtures the organic particle mass increases nearly linearly with the VOC burden, with a sensitivity exponent $\approx 1.2 \pm 0.2$, considerably lower than chamber systems. Such linearity implies that there are no disproportionate benefits of emission reductions. Rather, megacity OA pollution is not an inevitable convergence of non-linear effects, but can be addressed (much like in smaller urban areas) by rational and proportionate reductions in emissions. 
Photochemistry is the main driving force for the change in volatility distributions, pushing organic material from higher volatility to lower volatility, at least in the urban environment. In Table 1, aerosols that have undergone intense photochemical processing (OOA and its variants) show sensitivities very close to unity, while HOA, BBOA, and MOA - all presumably less processed by tropospheric chemistry - show higher sensitivities. Ultimately, the role of photochemistry may reverse, leading to net fragmentation rather than further functionalization. ${ }^{48,49}$ Recent studies suggest that OA chemistry may be more dynamic than previously believed, on both formation and removal sides, ${ }^{50}$ and it is likely that volatility distributions also evolve over the lifetime of the aerosol.

However, there are still large uncertainties in all methods used, whether based on volatility spectra from thermal denuders, OA/CO from aircraft observations, or models. Very few measurements of OA volatility distributions in urban (or any) environments have been reported. Given that most 3D models treat gas-particle partitioning using the equations described here (or slight variants thereof), additional comparisons between modeled and observed volatility distribution may be useful to evaluate whether such models can reasonably represent the sensitivity of OA to changing emissions of VOCs.

Acknowledgements: The National Center for Atmospheric Research is sponsored by the National Science Foundation. SM and JLT were partly supported by a grant from the US Department of Energy, Office of Science BER/DE-SC0006780. 


\section{REFERENCES:}

1 G. M. Hidy, B. R. Appel, R. J. Charlson, W. E. Clark, S. K. Friedlander and D. H. Hutchinson, J. Air Pollut. Control. Assoc., 1975, 25, 1106-1114.

2 S. I. Lamb, C. Petrowski, I. R. Kaplan and B. R. T. Simoneit, J. Air Poll. Control Assoc., 1980, 30, 1098-1115.

3 B. Finlayson-Pitts and J. N. Pitts, Chemistry of the Upper and Lower Atmosphere, Academic Press, 1999.

4 J. H. Seinfeld and S. N. Pandis, Atmospheric Chemistry and Physics: From Air Pollution to Climate Change, 2nd ed., John Wiley and Sons, Hoboken, New Jersey, 2006.

5 M. C. Jacobson, H.-C. Hansson, K. J. Noone and R. J. Charlson, Rev. Geophys., 2000, 38, 267-294.

6 M. Kanakidou, J. H. Seinfeld, S. N. Pandis, I. Barnes, F. J. Dentener, M. C. Facchini, R. Van Dingenen, B. Ervens, A. Nenes, C. J. Nielsen, E. Swietlicki, J. P. Putaud, Y. Balkanski, S. Fuzzi, J. Horth, G. K. Moortgat, R. Winterhalter, C. E. L. Myhre, K. Tsigaridis, E. Vignati, E. G. Stephanou, and J. Wilson, Atmos. Chem. Phys., 2005, 5, 1053-1123.

7 S. Fuzzi, M. O. Andreae, B. J. Huebert, M. Kulmala, T. C. Bond, M. Boy, S. J. Doherty, A. Guenther, M. Kanakidou, K. Kawamura, V.-M. Kerminen, U. Lohmann, L. M. Russell and U. Pöschl, Atmos. Chem. Phys., 2006, 6, 2017-2038, doi:10.5194/acp-6-2017-2006.

8 A. L. Robinson, N. M. Donahue, M. K. Shrivastava, E. A. Weitkamp, A. M. Sage, A. P. Grieshop, T. E. Lane, S. N. Pandis and J. R. Pierce, Science, 2007, 315, 1259-1262.

9 J. L. Jimenez et al., Science, 2009, 326, 1525-1529.

10 J. H. Kroll, N. M. Donahue, J. L. Jimenez, S. H. Kessler, M. R. Canagaratna, K. R. Wilson, K. E. Altieri, L. R. Mazzoleni, A. S. Wozniak, H. Bluhm, E. R. Mysak, J. D. Smith, C. E. Kolb and D. R. Worsnop, Nature Chem., 2011, 3, 133-139, doi:10.1038/nchem.948.

11 K. Tsigaridis, et al., Atmos. Chem. Phys., 2014, 14, 10845-10895, doi:10.5194/acp-14-10845-2014.

12 S. N. Pandis, N. M. Donahue, B. N. Murphy, I. Riipinen, C. Fountoukis, E. Karnezi, D. Patouliasa and K. Skyllakoua, Faraday Discuss., 2013, 165, 9-24, DOI: 10.1039/C3FD00108C.

13 R. Zhang, G. Wang, S. Guo, M. L. Zamora, Q. Ying, Y. Lin, W. Wang, M. Hu, and Y. Wang, Chem. Rev., 2015, 115, 3803-3855.

14 J. F. Pankow, Atmos. Environ., 1987, 21, 2275-2283.

15 J. F. Pankow, Atmos. Environ., 1994, 28, 185-188.

16 J. R. Odum, T. Hoffmann, F. Bowman, D. Collins, R. C. Flagan, and J. H. Seinfeld, Environ. Sci. Technol., 1996, 30, 2580-2585.

17 L. T. Molina, S. Madronich, J. S. Gaffney, E. Apel, B. de Foy, J. Fast, R. Ferrare, S. Herndon, J. L. Jimenez, B. Lamb, A. R. Osornio-Vargas, P. Russell, J. J. Schauer, P. S. Stevens and M. Zavala, Atmos. Chem. Phys., 2010, 10, 8697-8760.

18 S. Guo et al., Proc. Nat. Acad. Sci., 2014, www.pnas.org/cgi/doi/10.1073/pnas.1419604111.

19 K. Nguyen and D. Dabdub, Aerosol Sci. Techn., 2002, 36, 560-572. 
20 J. Chen, J. Lu, J. C. Avise, J. A. DaMassa, M. J. Kleeman, and A. P. Kaduwela, Atmos. Environ., 2014, 92, 182-190.

21 C. L. Blanchard, G. M. Hidy, S. Shaw, K. Baumann, and E. S. Edgerton, Atmos. Chem. Phys. Discuss., 2015, 15, 17051-17092.

22 S. Aksoyoglu, J. Keller, D. C. Oderbolz, I. Barmpadimos, A. S. H. Prévôt, and U. Baltensperger, Sensitivity of ozone and aerosols to precursor emissions in Europe, Int. J. Environ. Pollut., 2012, 50, DOI: 10.1504/IJEP.2012.051215.

23 N. M. Donahue, A. L. Robinson, C. O. Stanier, and S. N. Pandis, Environ. Sci. Technol, 2006, 40, 2635-2643.

24 B. Aumont, S. Szopa, and S. Madronich, Atmos. Chem. Phys., 5, 2497-2517, 2005.

25 B. Aumont, M. Camredon, C. Mouchel-Vallon, S. La, F. Ouzebidour, R. Valorso, J. LeeTaylor, and S. Madronich, Royal Soc. Chem. Faraday Discuss., 2013, 165, 105-122, doi:10.1039/C3FD00029J.

26 J. Ortega, Turnipseed, A., Guenther, A. B., Karl, T. G., Day, D. A., Gochis, D., Huffman, J. A., Prenni, A. J., Levin, E. J. T., Kreidenweis, S. M., DeMott, P. J., Tobo, Y., Patton, E. G., Hodzic, A., Cui, Y. Y., Harley, P. C., Hornbrook, R. S., Apel, E. C., Monson, R. K., Eller, A. S. D., Greenberg, J. P., Barth, M. C., Campuzano-Jost, P., Palm, B. B., Jimenez, J. L., Aiken, A. C., Dubey, M. K., Geron, C., Offenberg, J., Ryan, M. G., Fornwalt, P. J., Pryor, S. C., Keutsch, F. N., DiGangi, J. P., Chan, A. W. H., Goldstein, A. H., Wolfe, G. M., Kim, S., Kaser, L., Schnitzhofer, R., Hansel, A., Cantrell, C. A., Mauldin, R. L., and Smith, J. N., Atmos. Chem. Phys., 2014, 14, 6345-6367.

27 J. Lee-Taylor, J., A. Hodzic, S. Madronich, B. Aumont, M. Camredon, R. Valorso, Atmos. Chem. Phys., 2015, 15, 595-615, doi:10.5194/acpd-14-17999-2014.

28 M. Bilde M., Chemical Reviews, 2015, 115, 4115-4156, 2015.

29 C. D. Cappa and J. L. Jimenez, Atmos. Chem. Phys., 2010, 10, 5409-5424.

30 A. Paciga, E. Karnezi1,E. Kostenidou, L. Hildebrandt, M. Psichoudaki, G. J. Engelhart, B.-H. Lee, M. Crippa, A. S. H. Prévôt, U. Baltensperger and S. N. Pandis, Atmos. Chem. Phys. Discuss., 2015, 15, 22263-22289, doi:10.5194/acpd-15-22263-2015.

31 A. A. Presto and N. M. Donahue, Environ. Sci. Technol., 2006, 40, 3536-3543.

32 A. P. Grieshop, M. A. Miracolo, N. M. Donahue and A. L. Robinson, Environ. Sci. Technol., 2009, 43, 4750-4756.

33 Y. Nannoolal, J. Rarey and D. Ramjugernath, Fluid Phase Equil., 2008, 269(1-2), 117-133.

34 J. F. Pankow and K. C. Barsanti, Atmos. Environ., 2009, 43, 2829-2835.

35 A. Hodzic, B. Aumont, C. Knote, J. Lee-Taylor, S. Madronich and G. Tyndall, Geophys. Res. Lett., 2014, 41, doi:10.1002/2014GL060649.

36 R. Valorso, B. Aumont, M. Camredon, T. Raventos-Duran, C. Mouchel-Vallon, N. L. Ng, J. H. Seinfeld, J. Lee-Taylor and S. Madronich, Atmos. Chem. Phys, 2011, 11, 6895-6910.

37 L. I. Kleinman, S. R. Springston, P. H. Daum, Y.-N. Lee, L. J. Nunnermacker, G. I. Senum, J. Wang, J. Weinstein-Lloyd, M. L. Alexander, J. Hubbe, J. Ortega, M. R. Canagaratna, and J. Jayne, Atmos. Chem. Phys., 2008, 8, 1559-1575. 
38 L. I. Kleinman, P. H. Daum, Y.-N. Lee, G. I. Senum, S. R. Springston, J. Wang, C. Berkowitz, J. Hubbe, R. A. Zaveri, F. J. Brechtel, J. Jayne, T. B. Onasch and D. Worsnop, J. Geophys. Res., 2007, 112, D09310, doi:10.1029/2006JD007786.

39 A. P. Sullivan, R. E. Peltier, C. A. Brock, J. A. de Gouw, J. S. Holloway, C. Warneke, A. G. Wollny, and R. J. Weber, J. Geophys. Res., 2006, 111, D23S46, doi:10.1029/2006JD007072, 2006.

40 R. J. Weber, A. P. Sullivan, R. C. Peltier, A. Russell, B. Yan, M. Zheng, J. de Gouw, C. Warnke, C. Brock, J. S. Holloway, E. L. Atlas and E. Edgerton, J. Geophys. Res., 2007, 112, D13302, doi:10.1029/2007JD008408.

41 J. A. de Gouw, D. Welsh-Bon, C. Warneke, W. C. Kuster, L. Alexander, A. K. Baker, A. J. Beyersdorf, D. R. Blake, M. Canagaratna, A. T. Celada, L. G. Huey, W. Junkermann, T. B. Onasch, A. Salcido, S. J. Sjostedt, A. P. Sullivan, D. J. Tanner, O. Vargas, R. J. Weber, D. R. Worsnop, X. Y. Yu and R. Zaveri, Atmos. Chem. Phys., 2009, 9, 3425-3442.

42 T. Novakov and C. E. Corrigan, Microchim. Acta, 1995, 119, 157-166.

43 A. Karanasiou, M. C. Minguillón, M. Viana, A. Alastuey, J.-P. Putaud, W. Maenhaut, P. Panteliadis, G. Močnik, O. Favez, and T. A. J. Kuhlbusch, Atmos. Meas. Tech. Discuss., 2015, 8, 9649-9712, doi:10.5194/amtd-8-9649-2015.

44 C. Pio, M. Cerqueira, R. M. Harrison, T. Nunes, F. Mirante, C. Alves, C. Oliveira, A. Sanches de la Campa, B. Artiñano, and M. Matos, Atmos. Environ., 2011, 45, 6121-6132.

45 Z. Niu, F. Zhang, Z. Kong, J. Chen, L. Yin and L. Xu, J. Environ. Monit., 2012, 14, 2961-2967.

46 Z. Pusheng, D. Fan, Y. Yadong, H. Di, Z. Xiujuan, Z. Wenong, Y. Qing, and L. Huaiyu, Atmos. Environ., 2013, 71, 389-398.

47 M. C. Day, M. Zhang, and S. N. Pandis, Atmos. Environ., 2015, 12, 317-325.

48 A. Hodzic, S. Madronich, P. S. Kasibhatla, G. Tyndall, B. Aumont, J. L. Jimenez, J. Lee-Taylor and J. Orlando, Atmos. Chem. Phys., 2015, 15, 9253-9269.

49 K. Dzepina, C. Mazzoleni, P. Fialho, S. China, B. Zhang, R. C. Owen, D. Helmig, J. Hueber, S. Kumar, J. A. Perlinger, L. J. Kramer, M. P. Dziobak, M. T. Ampadu, S. Olsen, D. J. Wuebbles, and L. R. Mazzoleni, Atmos. Chem. Phys., 2015, 15, 5047-5068, doi:10.5194/acp-15-5047-2015.

50 A. Hodzic, P. S. Kasibhatla, D. S. Jo, C. Cappa, J. L. Jimenez, S. Madronich, and R. J. Park, Atmos. Chem. Phys. Discuss., 2015, 15, 32413-32468. 
Table 1: Volatility Distributions for Organic Aerosols, $\mu \mathrm{g} \mathrm{m}^{-3}$.

\begin{tabular}{|c|c|c|c|c|c|c|c|c|c|c|c|c|c|c|c|c|c|}
\hline & \multirow[b]{2}{*}{ Ref. } & \multicolumn{10}{|c|}{$\log _{10} c_{i}$} & \multirow[b]{2}{*}{3} & \multirow[b]{2}{*}{4} & \multirow[b]{2}{*}{5} & \multirow[b]{2}{*}{6} & \multirow[b]{2}{*}{ Sum } & \multirow[b]{2}{*}{ Sensitivity } \\
\hline & & -7 & -6 & -5 & -4 & -3 & -2 & -1 & 0 & 1 & 2 & & & & & & \\
\hline $\begin{array}{l}\text { Chamber, alpha-pinene }+ \\
\text { ozone. SOA formation vs. } \\
\text { VOC consumed }\end{array}$ & 31 & & & & & & 0.005 & 0.01 & 0.04 & 0.1 & 0.2 & 0.4 & & & & 0.71 & 1.75 \\
\hline Dilution of diesel POA & 8 & & & & & & 0.03 & 0.06 & 0.1 & 0.15 & 0.2 & 0.3 & 0.4 & 0.5 & 0.8 & 2.54 & 1.34 \\
\hline $\begin{array}{l}\text { Wood smoke, thermal } \\
\text { denuder }\end{array}$ & 32 & & & & & & 0.05 & 0 & 0.05 & 0.25 & 0.15 & 0.5 & 0 & 0.1 & & 1.00 & 1.64 \\
\hline $\begin{array}{l}\text { Diesel exhaust and } \\
\text { lubricating oil, dilution and } \\
\text { thermal denuder }\end{array}$ & 32 & & & & & & 0.01 & 0.01 & 0.04 & 0.21 & 0.18 & 0.5 & 0.1 & & & 1.00 & 1.79 \\
\hline $\begin{array}{l}\text { Mexico City (MILAGRO) } \\
\text { total Organic Carbon (OC) }\end{array}$ & 29 & & 1.5 & 1.6 & 1.6 & 1.7 & 1.8 & 2 & 2.5 & 4.1 & 8.3 & 20 & & & & 45.10 & 1.17 \\
\hline $\mathrm{HOA}$ & 29 & & 0.7 & 0.8 & 0.9 & 1 & 1.3 & 2.1 & 3.5 & 6.5 & 12 & 22 & & & & 50.80 & 1.28 \\
\hline BBOA & 29 & & & 0.1 & 0.3 & 0.6 & 1.3 & 2.4 & 4.3 & 7.5 & 14 & 24 & & & & 54.50 & 1.35 \\
\hline OOA & 29 & & 1.8 & 1.8 & 1.9 & 1.9 & 2 & 2.1 & 2.2 & 2.9 & 4.3 & 7.2 & & & & 28.10 & 1.10 \\
\hline LV-OOA & 29 & 4.5 & 3.5 & 2.5 & 1.7 & 1 & 0.6 & 0.3 & 0.2 & 0.1 & & & & & & 14.40 & 1.01 \\
\hline SV-OOA & 29 & & 1.2 & 1.5 & 1.8 & 2.1 & 2.8 & 3.4 & 4.4 & 5.8 & 7.5 & & & & & 30.50 & 1.14 \\
\hline $\begin{array}{l}\text { Paris (MEGAPOLIS) } \\
\text { HOA-Summer }\end{array}$ & 30 & & & & 0.12 & 0.13 & 0.08 & 0.03 & 0.05 & 0.58 & & & & & & 0.99 & 1.08 \\
\hline SVOOA-Summer & 30 & & & & 0.06 & 0.14 & 0.15 & 0.13 & 0.18 & 0.34 & & & & & & 1.00 & 1.19 \\
\hline LVOOA-Summer & 30 & 0.2 & 0.25 & 0.28 & 0.26 & 0.04 & & & & & & & & & & 1.03 & 1.00 \\
\hline COA-Summer & 30 & & & 0.13 & 0.15 & 0.08 & 0.2 & 0.08 & 0.37 & & & & & & & 1.01 & 1.14 \\
\hline MOA-Summer & 30 & & & & 0.03 & 0.03 & 0.05 & 0.28 & 0.41 & 0.2 & & & & & & 1.00 & 1.52 \\
\hline HOA-winter & 30 & & & & 0.11 & 0.09 & 0.07 & 0.12 & 0.11 & 0.5 & & & & & & 1.00 & 1.20 \\
\hline COA-winter & 30 & & 0.12 & 0.11 & 0.14 & 0.43 & 0.12 & 0.1 & & & & & & & & 1.02 & 1.02 \\
\hline BBOA-winter & 30 & & & & 0.2 & 0.09 & 0.08 & 0.14 & 0.1 & 0.4 & & & & & & 1.01 & 1.13 \\
\hline OOA-winter & 30 & & & & 0.3 & 0.09 & 0.07 & 0.09 & 0.1 & 0.35 & & & & & & 1.00 & 1.14 \\
\hline $\begin{array}{l}\text { MILAGRO day } 1 \\
\text { GECKO-A model }\end{array}$ & 27 & & & & 0.2 & 0.5 & 0.693 & 1.6 & 1.87 & 3.1 & 6.38 & 5 & 9.4 & 15 & 20 & 63.98 & 1.27 \\
\hline $\begin{array}{l}\text { BEACHON day1 } \\
\text { GECKO-A model }\end{array}$ & 27 & & & & 0.05 & 0.1 & 0.178 & 0.21 & 0.27 & 0.28 & 0.35 & 0.5 & 0.8 & 1.4 & 1.4 & 5.52 & 1.21 \\
\hline
\end{tabular}




\section{Figure Captions:}

Figure 1: Idealized gas-particle partitioning in a two-component system where one component is not volatile (seed), and the volatility $c$ of the other component is varied. The amount partitioned to the particle is shown on the left scale, while the thin curves and right scale shows local sensitivity (log-log slope) to changes in the total burden $t$. Units are arbitrary if consistent but for definiteness can be taken as $\mu \mathrm{g} \mathrm{m}^{-3}$ for all quantities.

Figure 2: Growth of particle mass computed for the volatility distributions measured in chambers, including secondary organic aerosols formed by ozonolysis of $\alpha$-pinene,${ }^{31}$ diesel exhaust, ${ }^{8}$ and wood smoke and diesel/oil mixtures. ${ }^{32}$ Crosses show where gas-particle partitioning was calculated. Lines with $\log$-log slopes of 1 and 2 are also shown, with arbitrary vertical offsets.

Figure 3: Volatility distribution of organic aerosols in Mexico City outflow predicted by the GECKO-A model, ${ }^{27}$ shown as the total amount available $t_{\mathrm{i}}$ (particle + gas) in each decadal saturation range (bin) $c_{\mathrm{i}}$. The distribution is shown for five days, the first of which represents the urban environment while the later ones represent multiday outflow. Dashed curves show particle phase.

Figure 4: Normalized sensitivity coefficient of the production of organic aerosols by VOCs, within Mexico City (red) and its outflow (blue), calculated using volatility distributions from the GECKO-A model. ${ }^{27}$ Negative times represent model spin-up. 


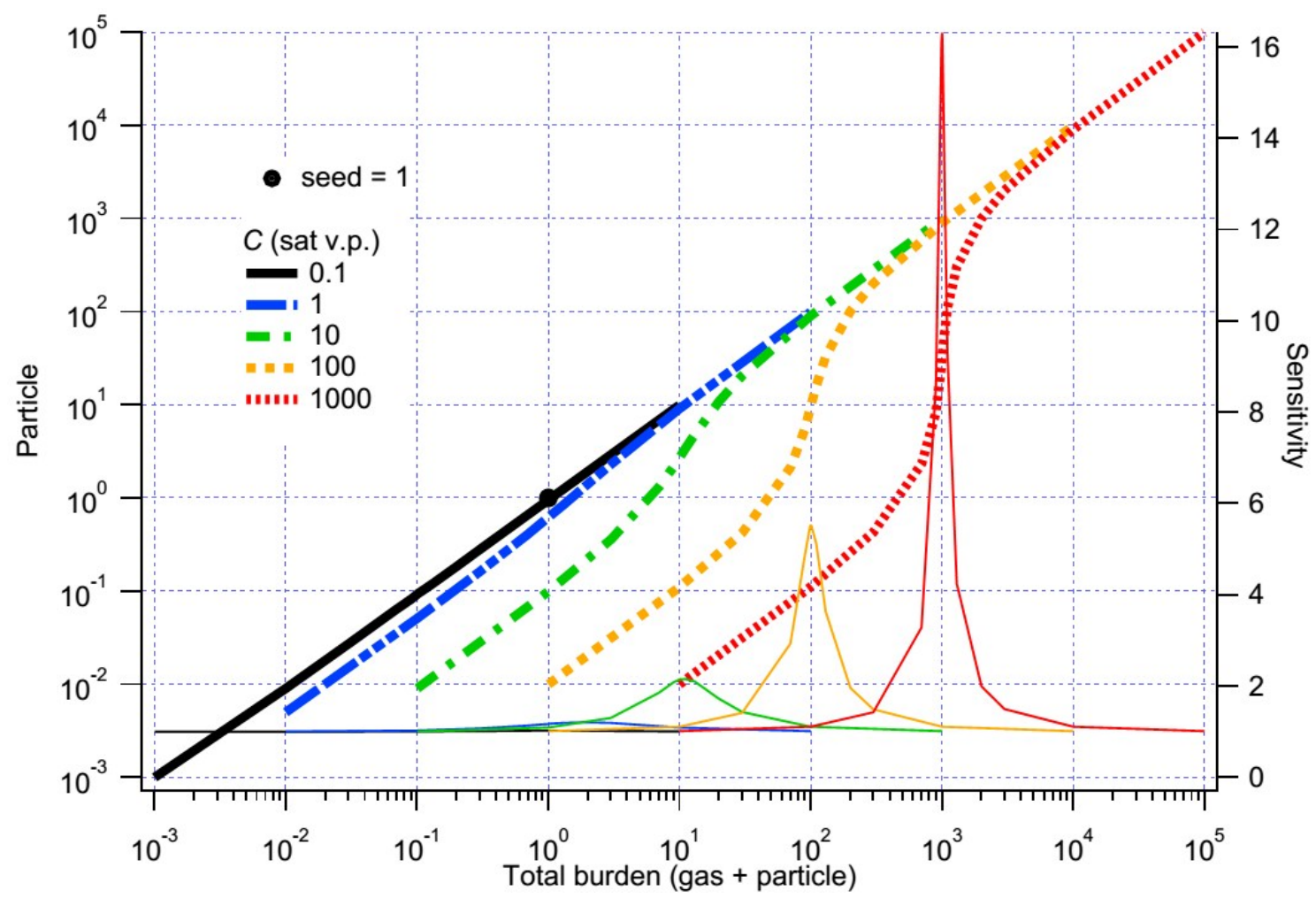

Figure 1: Idealized gas-particle partitioning in a two-component system where one component is not volatile (seed), and the volatility $c$ of the other component is varied. The amount partitioned to the particle is shown on the left scale, while the thin curves and right scale shows local sensitivity (log-log slope) to changes in the total burden $t$. Units are arbitrary if consistent but for definiteness can be taken as $\mu \mathrm{g} \mathrm{m}^{-3}$ for all quantities. 


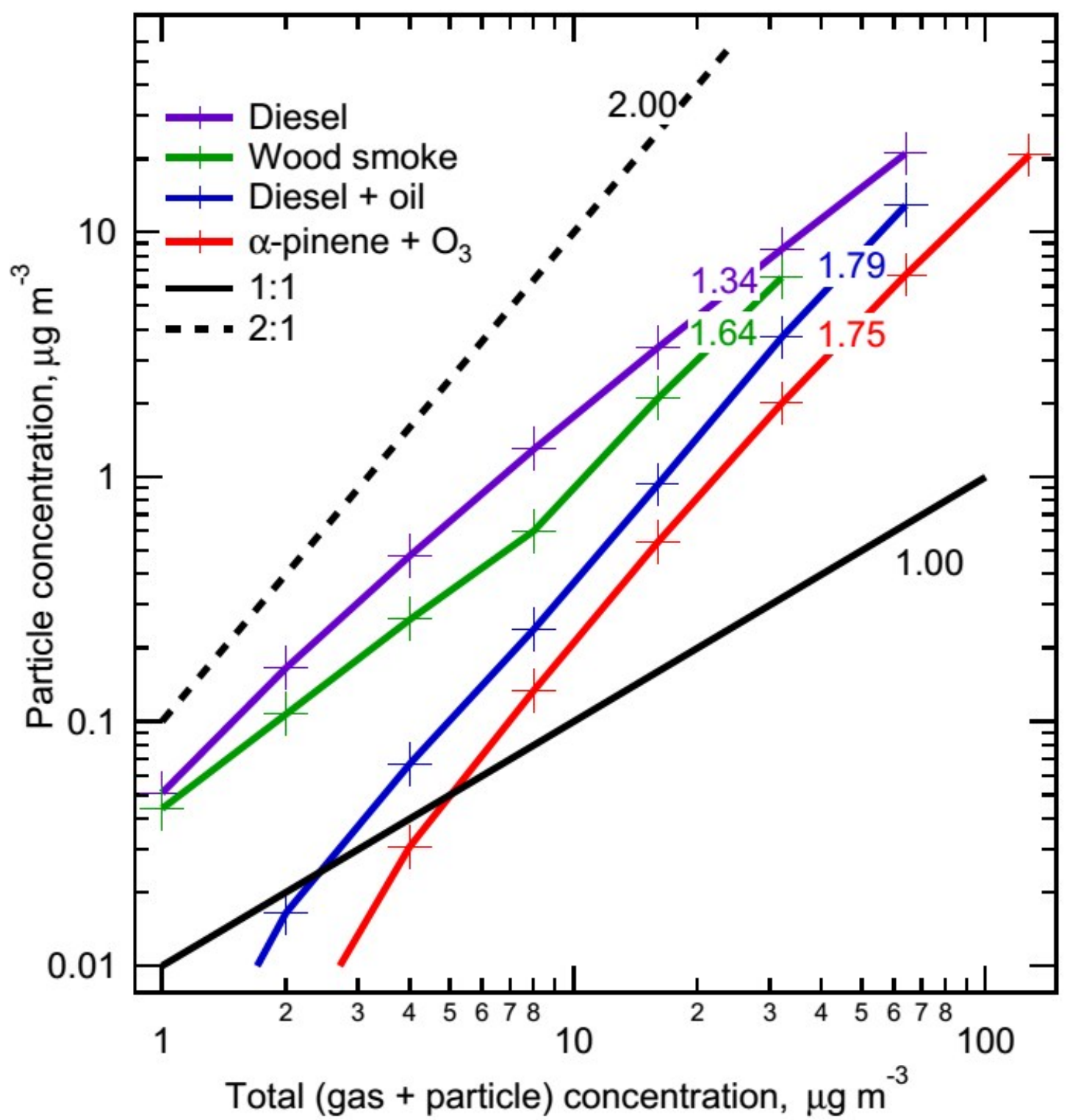

Figure 2: Growth of particle mass computed for the volatility distributions measured in chambers, including secondary organic aerosols formed by ozonolysis of $\alpha$-pinene,${ }^{31}$ diesel exhaust, ${ }^{8}$ and wood smoke and diesel/oil mixtures. ${ }^{32}$ Crosses show where gas-particle partitioning was calculated. Lines with $\log -\log$ slopes of 1 and 2 are also shown, with arbitrary vertical offsets. 


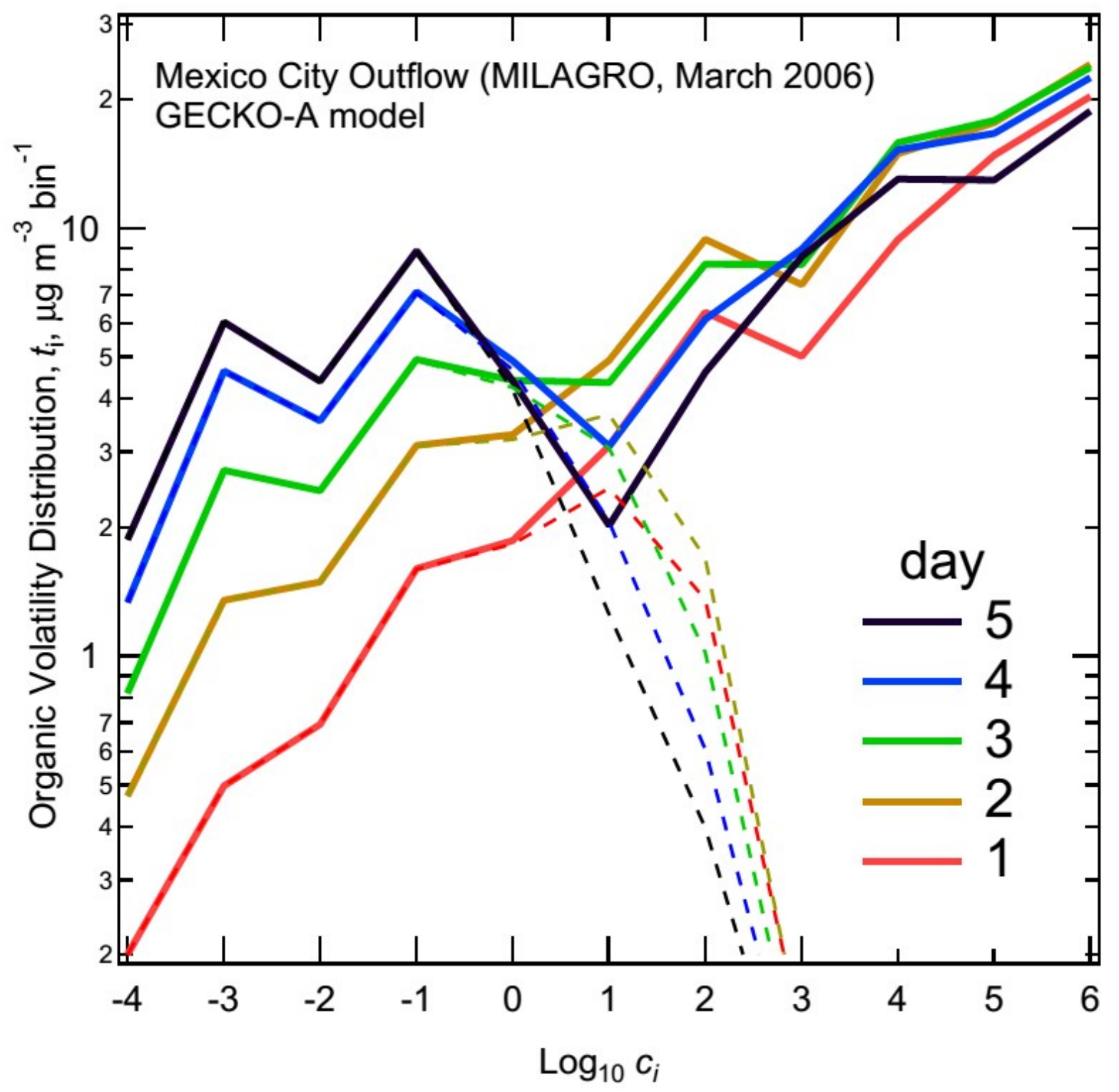

Figure 3: Volatility distribution of organic aerosols in Mexico City outflow predicted by the GECKO-A model, ${ }^{27}$ shown as the total amount available $t_{\mathrm{i}}$ (particle + gas) in each decadal saturation range (bin) $c_{\mathrm{i}}$. The distribution is shown for five days, the first of which represents the urban environment while the later ones represent multiday outflow. Dashed curves show particle phase. 


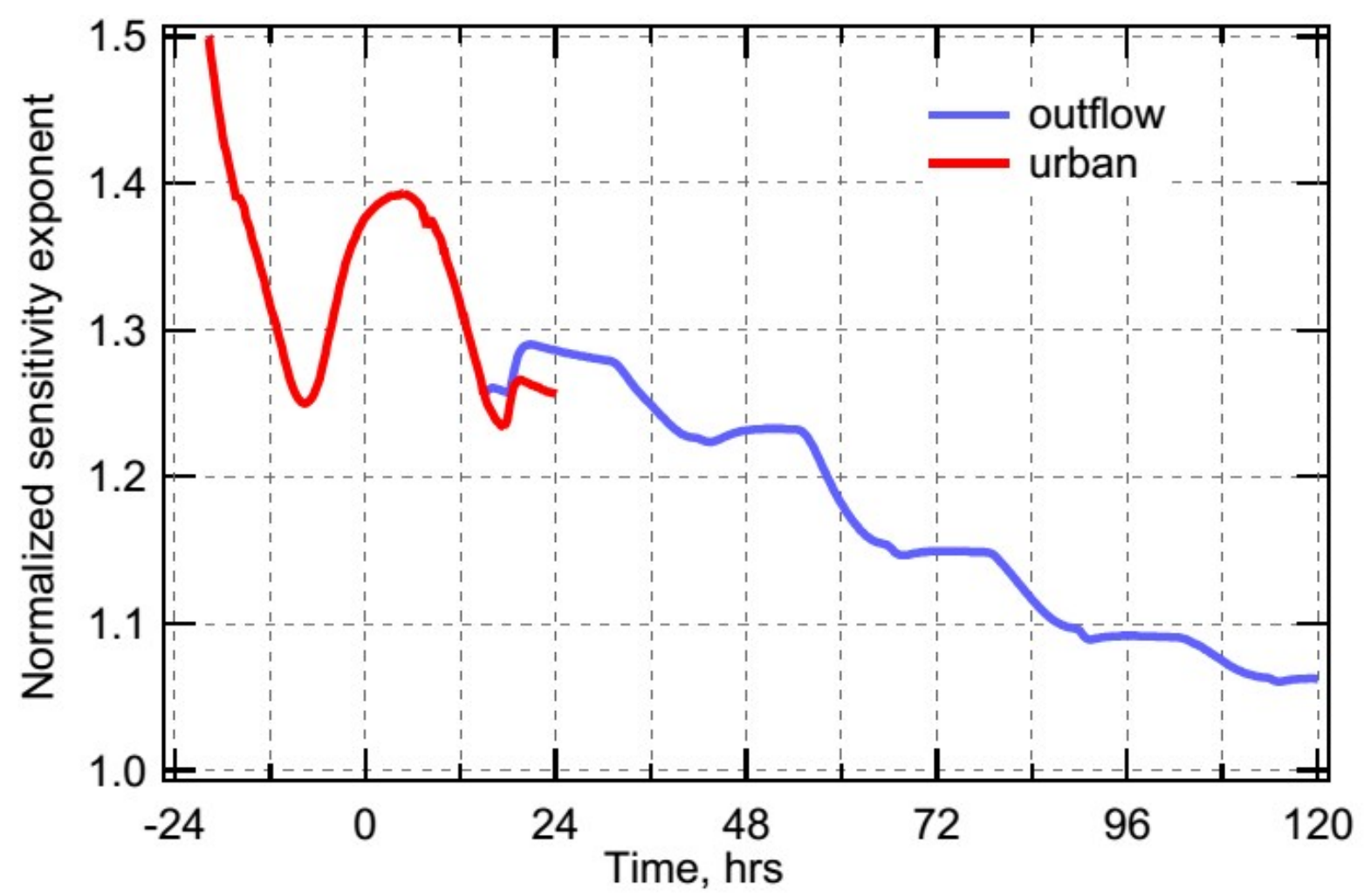

Figure 4: Normalized sensitivity coefficient of the production of organic aerosols by VOCs, within Mexico City (red) and its outflow (blue), calculated using volatility distributions from the GECKO-A model. ${ }^{27}$ Negative times represent model spin-up. 